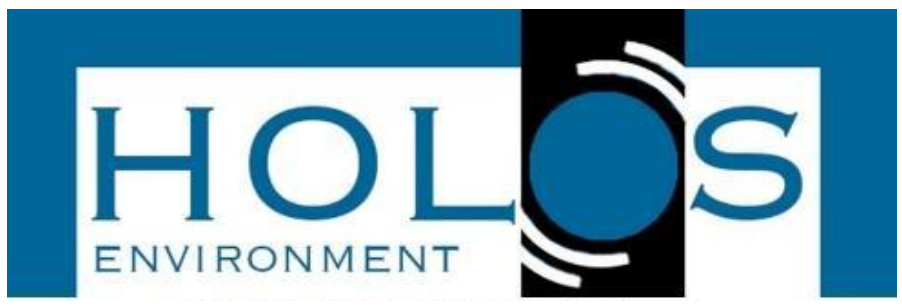

\title{
UTILIZAÇÃO DA FERRAMENTA LCM DO IDRISI /TAIGA PARA ANÁLISE DE PERDAS E GANHOS NO USO DA TERRA NA ZONA DE AMORTECIMENTO DA ESTAÇÃO ECOLÓGICA DE ASSIS (SP)
}

\section{USING THE LAND CHANGE MODELER TOOL FROM IDRISI /TAIGA TO ANALYZE LAN USE GAINS AND LOSSES FROM THE ASSIS (SP) ECOLOGICAL STATION DAM ZONE}

\author{
Layla Cristina de Freitas Assalve1; Daniela Fernanda da Silva Fuzzo²
}

Artigo recebido em: 12/01/2021 e aceito para publicação em: 03/02/2021. DOI: http://doi.org/10.14295/holos.v21i2.12439

\begin{abstract}
Resumo: Ao longo do tempo foram criados diversos tipos de manejos adequados para cada Unidade de Conservação (UCs), dentre eles, a Zona de Amortecimento (ZA) surge com o papel de filtrar os impactos negativos das atividades que ocorrem ao seu redor. Desta forma, o objetivo deste trabalho foi analisar as modificações do uso da terra na ZA da Estação Ecológica de Assis - SP, nos anos 2000 e 2017. Para a realização do trabalho foram utilizadas imagens dos satélites Landsat 5/TM e Landsat 8/OLI, as imagens foram processadas em ambiente SIG e geradas os mapeamentos de perdas e ganhos utilizando o módulo Land Change Modeler (LCM) do software Idrisi-Taiga, o qual apresenta grande importância para a realização de estudos ambientais. Foi possível observar, a redução da pastagem e o aumento das culturas temporárias na porção norte e leste da área, nesses dezessete anos analisados, obteve um ganho de área de 12,29\%. Destaca-se que o entorno se encontra tomado integralmente por cultura temporária e silvicultura, que afetam a conservação, podendo gerar a perda da biodiversidade e o desmatamento neste local, sendo assim o conhecimento dos parâmetros analisados permite a utilização de técnicas adequadas para a preservação efetiva. Portanto, a utilização de dados orbitais pode contribuir ao monitoramento das UCs evitando a degradação ambiental.
\end{abstract}

Palavras-chave: Sensoriamento Remoto. LCM. Classificação.

Abstract: Over time, several types of appropriate management were created for each Conservation Unit (Ucs), among them, the Damping Zone (ZA) appears with the role of filtering the negative impacts of the activities that occur around it. Thus, the objective of this study was to analyze the land use modifications in the ZA of the Assis Ecological Station - SP, in the years 2000 and 2017. Images of the Landsat 5/TM and Landsat 8/OLI satellites were used to perform the study. The images were processed in GIS environment and generated the mapping of losses and gains using the Land Change Modeler module of the Idrisi-Taiga software, which is very important for environmental studies. It was possible to observe, initially, the gradual reduction of the pasture and the increase of the temporary crops in the north and east of the area in these seventeen years analyzed, obtained an area gain of $12.29 \%$. It is noteworthy that the surroundings are completely taken up by tempory culture and forestry, that affect the conservation can generate the loss of biodiversity in this place, and therefore the knowledge of the analyzed parameters allows the use of appropriate techniques for effective preservation. Therefore, the use of orbital data can contribute to the monitoring of Ucs avoiding environmental degradation.

Keywords: Remote Sensing. LCM. Classification.

\footnotetext{
${ }^{1}$ Universidade Federal de São Carlos (UFSCar), São Carlos, SP. E-mail: (laylaassalve@hotmail.com)

2 Universidade Estado de Minas Gerais (UEMG), Unidade Frutal, MG. E-mail: (daniela.fuzzo@uemg.br)
} 


\section{NTRODUÇÃO}

O estabelecimento de espaços especialmente protegidos é uma das ferramentas mais utilizadas atualmente para a conservação da natureza. Trata-se de separar algumas porções do território e limitar ali o uso da terra e dos recursos naturais. Não há dúvida de que essa é uma estratégia importante e necessária diante da ocupação desenfreada da terra e do uso predatório dos recursos naturais que a humanidade vem, há tempos, protagonizando. A implementação de tal ferramenta, entretanto, tem enfrentado inúmeros desafios. Parte deles tem relação com a maneira como essas áreas protegidas foram - e em alguns casos, ainda são - estabelecidas (BENSUCAN, 2006).

As Unidades de Conservação (Uc) são hoje uma das melhores estratégias de proteção ao patrimônio natural, assim como os processos ecológicos que regem os ecossistemas, os recursos abióticos e bióticos, além da manutenção da biodiversidade. Embora existam várias formas de proteção, a criação destas áreas corresponde a mais básica e efetiva forma de se alcançar esse objetivo (VIEIRA et al., 2013).

Tem sido um grande desafio gerir um sistema de UCs de modo a garantir sua sustentabilidade em longo prazo, além dos inúmeros problemas relativos à área da própria unidade, como a regularização fundiária, a fiscalização e a implantação da infraestrutura, os gestores enfrentam diversas dificuldades de relacionamento com a população lindeira e de controle dos impactos das atividades socioeconômicas desenvolvidas no entorno das UCs (BRASIL, 2015).

Bensucan (2006) afirma que o Brasil conta com um Sistema Nacional de Unidades de Conservação - Snuc (Lei oㅜ 9.985, de 2000) - que norteia as políticas públicas e dispões sobre os instrumentos de planejamento das áreas protegidas. Segundo a lei, a zona de amortecimento (ZA) é o "entorno de uma unidade de conservação, onde as atividades humanas estão sujeitas a normas e restrições específicas, com o propósito de minimiza os impactos negativos sobre a unidade". Não resta dúvidas de que há necessidade de se normatizar as atividades das circunvizinhanças da unidade, pois estas podem afetar a integridade da área protegida. Antes da lei do Snuc, a resolução do Conselho Nacional do Meio Ambiente (Conama) que definia o entorno das unidades de conservação como uma faixa de 10 
km circundado os limites da área. Porém, com a criação da Snuc no art. 25 prevê, que a zona de amortecimento e os corredores ecológicos serão definidos caso a caso.

Sobre essa premissa, a aplicação dos estudos voltados ao sensoriamento remoto e a cobertura de uso da terra, principalmente em locais que sofrem constantes interferências antrópicas, se torna uma importante ferramenta cuja precisão pode contribuir para que haja resultados positivos na preservação da biodiversidade nestes locais.

Trabalhos como de Fengler et al. (2012) e Ribeiro et al. (2017) mostram a importância dessa ferramenta para a análise da ZA, destacando o uso do sensoriamento remoto eficiente para a gestão da Unidade de Conservação e devido ao seu desenvolvimento tecnológico atualmente serem mais baratos e acessíveis. Vários estudos em sensoriamento remoto que utilizam produtos como o índice de vegetação NDVI (Índice de Vegetação por Diferença Normalizada), por exemplo, podem fornecer dados de excelente qualidade, produzindo informações para classificações de cobertura e uso da terra, como aponta o trabalho de Rosendo et al., (2007).

Franco et al. (2011) afirma que o NDVI representa uma técnica amplamente utilizada no monitoramento, por indicarem a presença e condições da vegetação, além de auxiliar na gestão, contribuir para a conservação, preservação e monitoramento das mudanças na paisagem.

Segundo Leite e Rosa (2012), o conhecimento e o monitoramento do uso da terra são primordiais para a compreensão dos padrões de organização do espaço, uma vez que suas tendências possam ser analisadas, o autor afirma que esse monitoramento consiste em buscar conhecimento de toda a utilização por parte da sociedade ou, quando não utilizado, a caracterização de tipos de categorias de vegetação natural que reveste o solo, como também suas respectivas localizações, ou seja, de forma sintética, a expressão "uso da terra" pode ser entendida como sendo a forma pela qual o espaço está sendo ocupado pelo ser humano.

As mudanças no uso e cobertura da terra estão ligadas de forma complexa ao desenvolvimento econômico, ao crescimento da população, ao avanço tecnológico e as alterações ambientais (VIEIRA et al., 2013). O IBGE (2013) destaca a importância dos mapeamentos de uso e cobertura da terra como sendo uma importante ferramenta de planejamento e tomada de decisão. 
A Estação Ecológica de Assis foi criada em 21 de setembro de 1992 sobre o decreto de ㄲo35.697 e enquadrasse na categoria de Unidade de Conservação de proteção integral. Segundo o plano de manejo, corresponde a $10 \%$ das áreas de cerrado protegidas em Unidades de Conservação no estado de SP, preserva predominantemente vegetação de cerrado lato sensu. Portanto, este trabalho tem como objetivo mapear as mudanças ocorridas na Zona de Amortecimento da Estação Ecológica de Assis, nos anos de 2000 e 2017 e pontuar as perdas e ganhos no uso da terra durante o período analisado.

\section{MATERIAL E MÉTODOS}

A Estação Ecológica de Assis (EEA), encontra-se entre as coordenadas

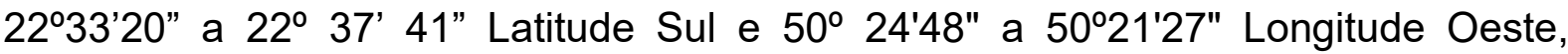
localizada no município de Assis, situado a sudoeste do Estado de São Paulo (Figura 1). Segundo Pinheiros et al (2009) a EEA está inserida em uma zona de transição entre os tipos climáticos Cwa e Cfa, segundo a classificação de Köppen (1948), caracterizada como subtropical, com chuvas concentradas no verão e estação seca no inverno, com duração variável; as médias anuais de temperatura e precipitação são $21,8^{\circ} \mathrm{C}$ e $1.400 \mathrm{~mm}$.

Figura 1 - Localização da área de estudo

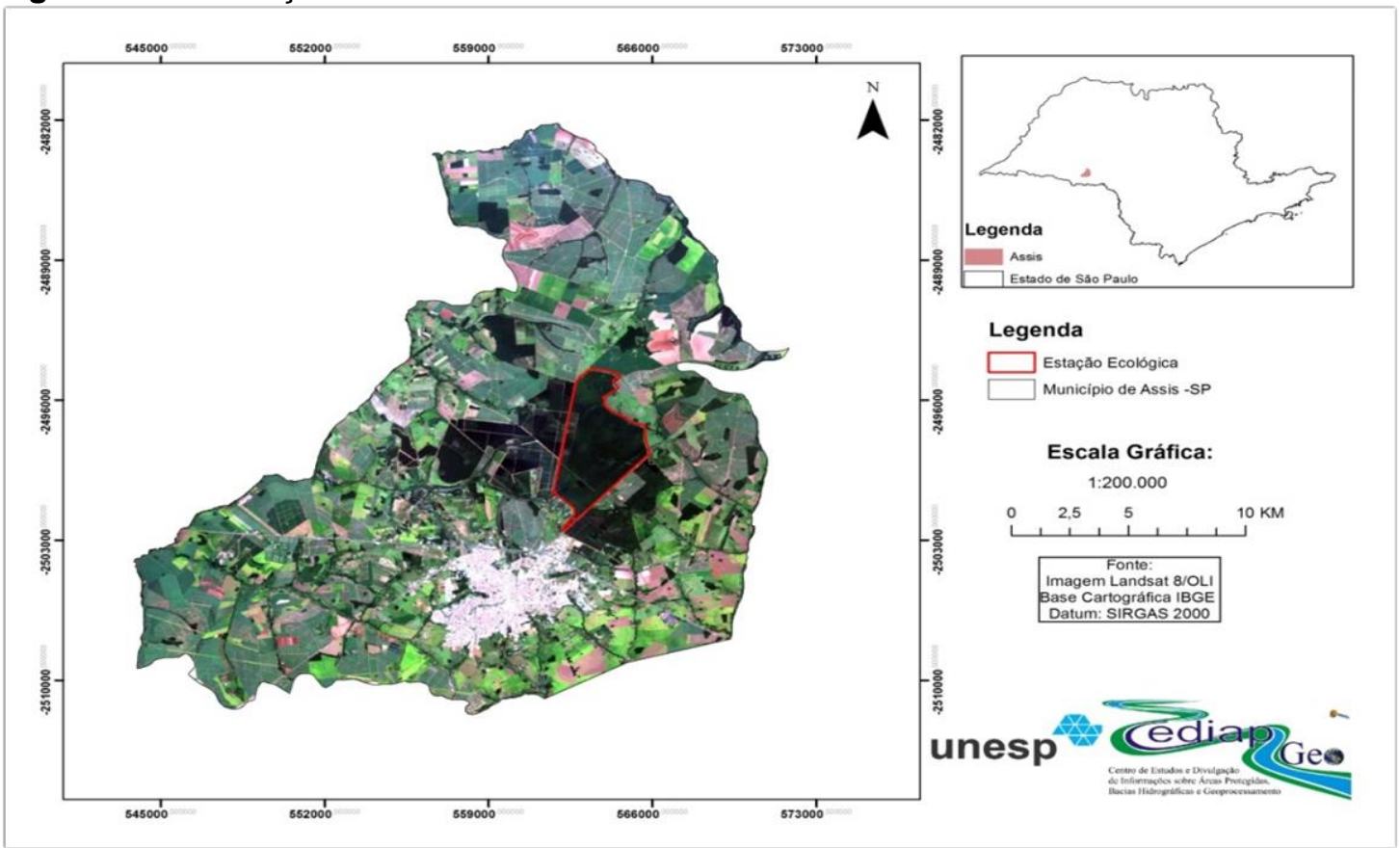

Fonte: Elaborado pelos autores (2017). 
A região da Estação Ecológica é constituída por rochas ígneas (pertencentes à Formação Serra Geral) e rochas sedimentares (da Formação Adamantina), ambas de idade predominantemente mesozóica; e por depósitos sedimentares recentes, de idade cenozoica. Pertence à unidade morfoestrutural denominada Bacia Sedimentar do Paraná e à unidade morfoescultural Planalto Ocidental Paulista - Planalto Centro Ocidental. Predominam formas de relevo denudacionais, relevo levemente ondulado, com predomínio de colinas amplas e baixas de topos convexos (Dc) na região sul do município, ou topos aplainados ou tabulares (Dt) encontrados na região norte, as altitudes variam entre $300 \mathrm{~m}$ e $600 \mathrm{~m}$ e as declividades médias predominantes das vertentes estão entre $2 \%$ e $10 \%$. Os entalhamentos médios dos vales são inferiores a $20 \mathrm{~m}$ e as dimensões interfluviais médias estão entre $1750 \mathrm{~m}$ e $3750 \mathrm{~m}$ (BONGIOVANNI, 2008).

Os solos da Estação Ecológica de Assis, segundo Rossatto et al. (2011) são geralmente arenosos, ácido e de baixa fertilidade. É composto pelos seguintes tipos de solo: Latossolo Vermelho distrófico típico (LVd); Latossolo Vermelho-Amarelo distrófico típico (LVAd); Latossolo Amarelo distrófico típico (LAd) e Gleissolo Háplico distrófico argissólico (GXbd). Trata-se de uma das áreas mais ao sul da extensa região de domínio do Cerrado, onde a vegetação savânica forma, com a floresta estacional semidecidual, um mosaico, geralmente associado às características físico-químicas dos solos. A vegetação caracteriza-se como cerrado sensu lato, predominando a fisionomia cerradão (ROSSATTO et al., 2011).

Foram obtidas as imagens de satélite Landsat 5/TM e Landsat 8/OLI, para os anos de 2000 e 2017, do Instituto Nacional de Pesquisas Espaciais (INPE), as imagens apresentam órbita 7/ponto 222, com resolução espacial de $30 \mathrm{~m}$, e resolução temporal de 16 dias. O limite municipal de Assis foi adquirido da base cartográfica do Instituto Brasileiro de Geografia e Estatística (IBGE) no formato de shapefile, na escala de 1:250.000 e referenciado no Sistema Geodésico Brasileiro (SIRGAS 2000). O limite da Estação Ecológica utilizado foi adquirido no Ministério do Meio Ambiente também em formato shapefile e encontram-se em Sistema de Coordenadas Geográficas, South American Datum 1969 (SAD1969).

Para melhor conhecimento e delimitação da área de estudo, foram feitas as composições coloridas RGB432 para o ano de 2000 e RGB543, para 2017. Segundo Alvarenga et al (2014) essas bandas apresentam reflectância na região do visível (vermelho) e do infravermelho próximo do espectro eletromagnético. $\mathrm{Na}$ faixa 
espectral do vermelho, há alta absorção de energia solar devido à presença da clorofila e isso ocasiona baixa reflectância. Por sua vez, na faixa do infravermelho próximo, essa absorção é baixa e resulta em alta reflectância. Portanto, a combinação dessas duas faixas espectrais realça as áreas de vegetação nas imagens.

Para destacar as áreas com maior rigor vegetativo, foram realizados os cálculos de bandas para obtenção do índice de vegetação - NDVI, que é a razão entre a diferença das refletividades das bandas no infravermelho próximo e no vermelho e pela soma dessas mesmas refletividades (ROUSE et al., 1973). É o espectro que separa a vegetação verde do brilho do solo de fundo. O NDVI é um indicador sensível da quantidade e condição da vegetação, cujos valores variam no intervalo de -1 a 1 . Nas superfícies que contêm água ou nuvens, esta variação é sempre menor do que 0 . É expresso como a diferença entre a banda do infravermelho e do vermelho pela soma das bandas:

$N D V I=I V P-V / I V P+V$

onde: IVP e V são os valores de reflectância das bandas 3 (vermelho) e 4 (infravermelho próximo) do Landsat 5 TM e das bandas 4 (vermelho) e 5 (infravermelho) do Landsat 8OLI.

A escolha da área de estudo foi baseada no critério por ser uma das poucas áreas com cobertura vegetal nativa da região, visto que, atualmente encontra-se tomada por outras atividades em seu entorno. Para a análise da Zona de Amortecimento, foi gerado um buffer, isto é, um polígono criado em uma distância específica no entorno da unidade de conservação. Está foi delimitada baseada na Resolução Conama n 13 de 06 de dezembro de 1990, que estabelece um raio de 10 $\mathrm{km}$ a partir da área protegida. Esses procedimentos foram realizados e analisados por meio do software ARCGIS-10.3, licença disponível no laboratório de geoprocessamento na UNESP Campus de Ourinhos, para aplicação das técnicas de geoprocessamento.

Para classificação do uso da terra, foram identificadas as diferentes classes por meio do processo de vetorização e para atribuição dos diferentes tipos de coberturas foram adotadas como referencial teórico o Manual Técnico do Uso da Terra do IBGE. Foram aplicados o cálculo de área por meio dos polígonos de cada classe através da tabela de atributo, também por meio de ferramentas do software ARCGIS-10.3. 
Para as análises de perdas e ganhos, foi utilizado o módulo Land Change Modeler (LCM) do software Idrisi - Taiga, licença disponível no laboratório de geoprocessamento na UNESP Campus de Ourinhos. Este aplicativo mostra-se de grande importância para a realização de estudos ambientais, uma vez que, permite analisar as alterações ocorridas numa paisagem, modelar o potencial de transição das classes de cobertura, bem como avaliar os planos de intervenção para a manutenção da sustentabilidade ecológica. O módulo LCM usa como dados de entrada do modelo dois mapas da paisagem, com datas diferentes (época inicial e final). A partir destes mapas, os modeladores realizam a estimativa da quantidade de mudanças, com base em cadeia de Markov, resultando em matrizes de transição. Esta etapa de análise de mudança permite gerar gráficos com balanço de perdas e ganhos entre as classes (ZANATA, 2014). Os algoritmos da cadeia de Markov foram desenvolvidos pelo matemático russo Andrei Andreyevich Markov (1865 - 1922), como um modelo matemático particular de processo estocástico, que permite fazer uma previsão estimada do estado futuro de um sistema (Ricobom et al., 2017).Estudos realizados aplicando o módulo LCM tem se mostrado eficaz para a análise do uso e cobertura da terra destacam-se trabalhos como o de Zanata (2014); Santos (2015); Criado (2016). Esse método demostra a importância das técnicas de sensoriamento remoto e geoprocessamento quando trabalhado em análise ambiental.

\section{RESULTADOS E DISCUSSÃO}

Com a classificação, foi possível mapear oito tipos diferentes de uso e cobertura da terra na área de estudo, são elas: pastagem, área urbana, mata ciliar, silvicultura, cultura temporária, floresta, solo exposto e edificações. O resultado do processamento obtido revela as expressivas alterações na cobertura da terra

As Figuras 2 e 3 apresentam os mapas de classificação nos anos analisados (2000 e 2017), referentes à zona de amortecimento da Estação Ecológica de Assis. Pode-se compreender que a área se baseia no cultivo agrícola. É possível observar, inicialmente, a redução gradativa da pastagem e o aumento das culturas temporárias na porção norte e a leste nesses dezessete anos. Ficou evidente o aumento da silvicultura a oeste e a expansão da área urbana ao sul. Há evidencias também da conservação de florestas em uma área próxima da Unidade de conservação e da mata ciliar em diversos pontos da zona de amortecimento. 
Figura 2 - Mapa de classificação do uso e cobertura da terra, na zona de amortecimento da Estação Ecológica de Assis - SP para o ano de 2000

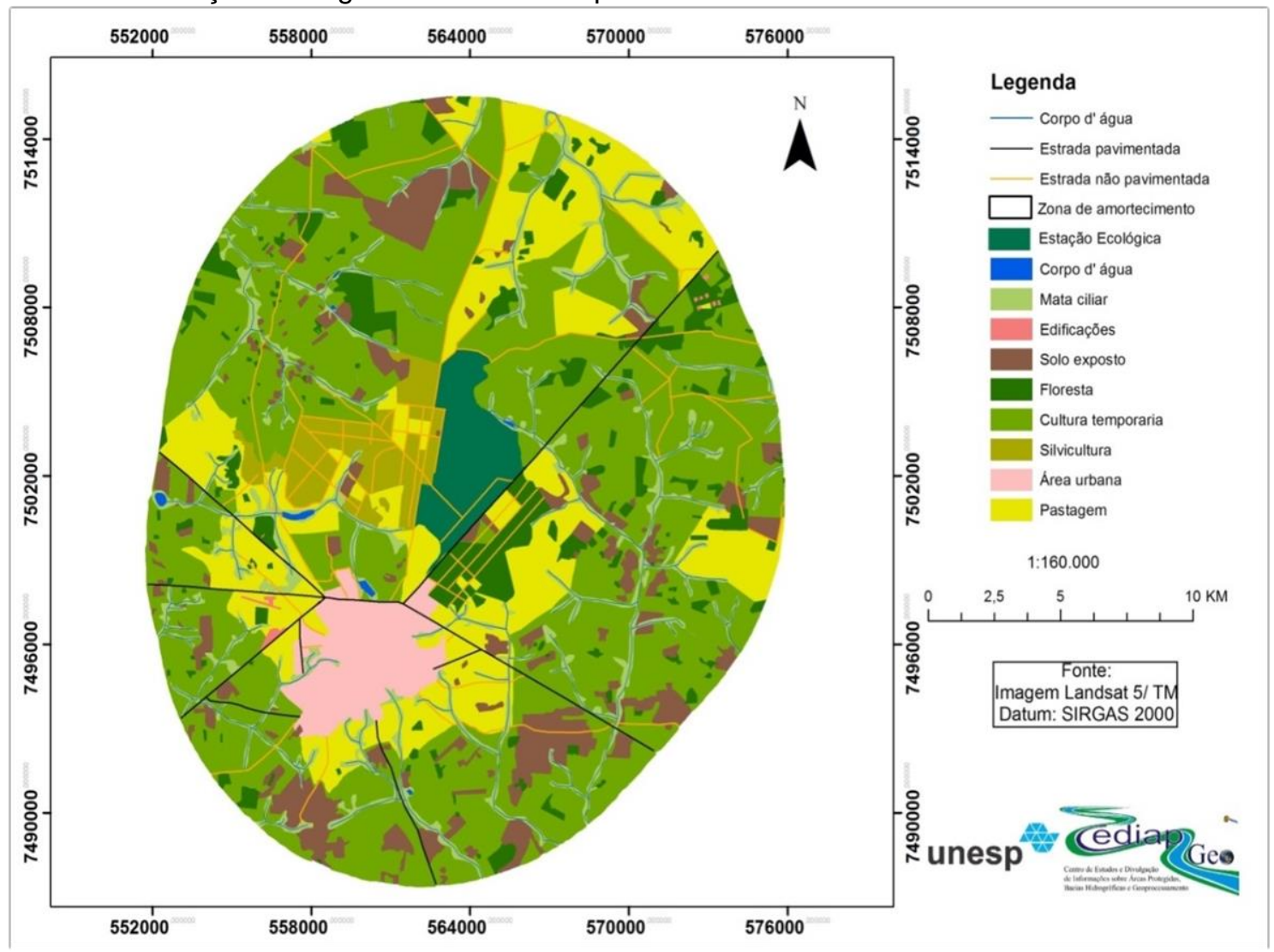

Fonte: Elaborado pelos autores (2017).

Analisando o uso e cobertura da terra no ano 2000 (Figura 2), observamos que a cobertura da terra que mais se destacava neste ano, era a cultura temporária, dada à sua relevância para cultivo de cana-de-açúcar. O segundo uso em destaque foram às áreas de pastagem, que alcançam a segunda maior área da zona de amortecimento. A área urbana nesta época já correspondia um tamanho expressivo. Foram observadas também, outras formas de ocupação como a silvicultura, os resquícios de floresta e as matas ciliares.

Em 2017 ocorreram significativas mudanças em relação a segunda maior área, que é a pastagem. A pastagem cedeu espaço para a área urbana e para a cultura temporária. A cultura temporária mantém como a maior área da zona de amortecimento. Podemos destacar à silvicultura, que ocupa uma área muito próxima da Estação Ecológica, e a mata ciliar, que obtiveram um crescimento relativo, e as florestas que mostraram uma redução.

$\mathrm{Na}$ Tabela 1, ferente as figuras 2 e 3, apresenta os tamanhos das áreas calculadas, nos diferentes tipos de uso, onde nota-se as mudanças através das áreas. 
Figura 3 - Mapa de classificação do uso e cobertura da terra na zona de amortecimento da Estação Ecológica de Assis - SP do ano 2017

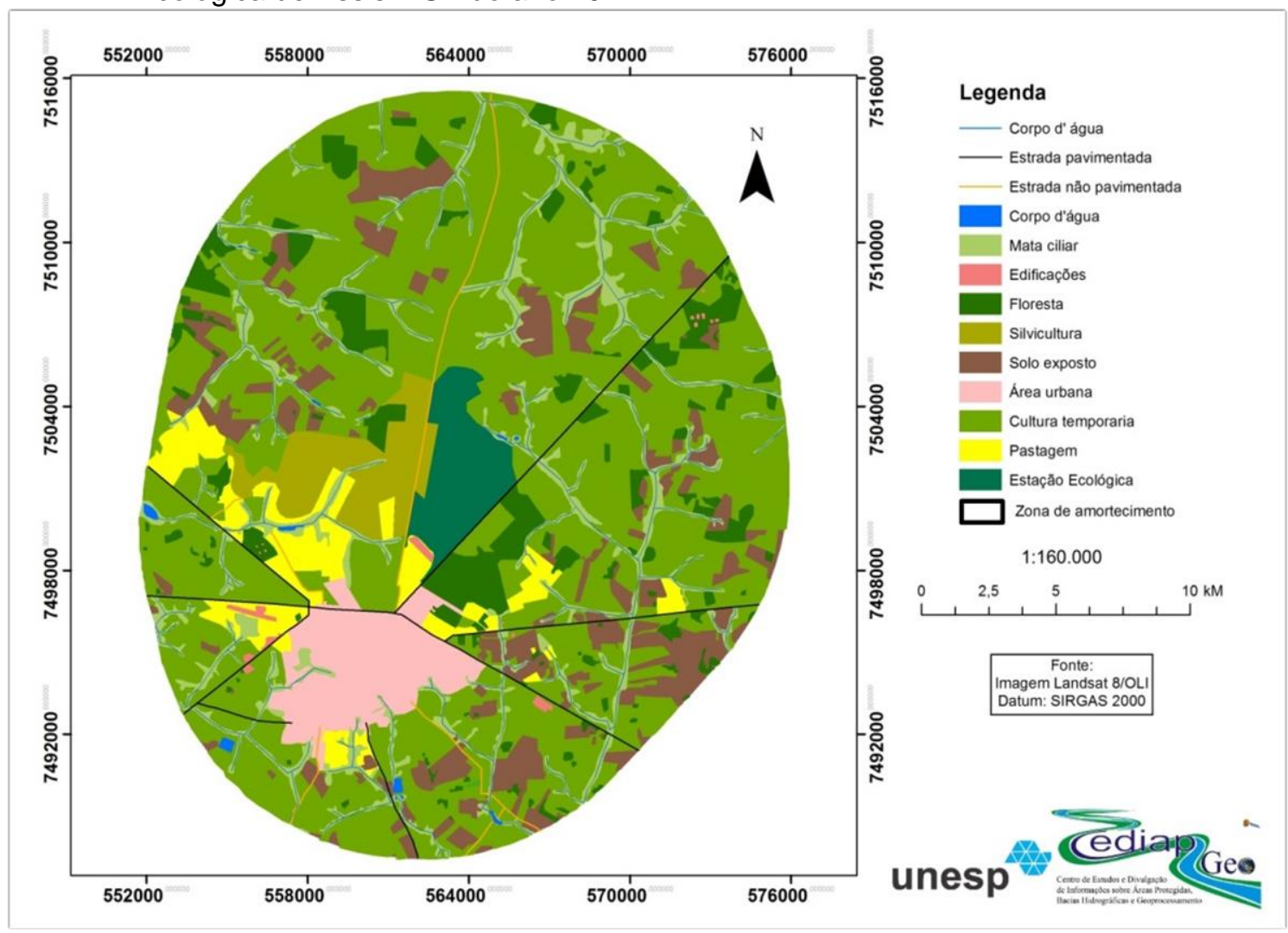

Fonte: Elaborado pelos autores (2017).

Tabela 1 - Obtenção dos valores dos polígonos classificados em cada ano

\begin{tabular}{ccc}
\hline Classes & $\begin{array}{c}\text { Área Calculada } \\
\mathbf{2 0 0 0}(\mathbf{h a})\end{array}$ & $\begin{array}{c}\text { Área Calculada } \\
\mathbf{2 0 1 7}(\mathbf{h a})\end{array}$ \\
\hline EEA & 1.598 & 1.713 \\
Pastagem & 11.114 & 3.288 \\
Área Urbana & 2.153 & 2.705 \\
Silvicultura & 1.983 & 2.705 \\
Mata Ciliar & 4.346 & 5.011 \\
Cultura Temporária & 35.800 & 44.408 \\
Floresta & 3.751 & 3.965 \\
Solo exposto & 4.641 & 5.385 \\
Edificações & 67 & 119 \\
\hline
\end{tabular}

Fonte: Elaborado pelos autores (2017).

Analisando a Tabela 1, pode-se observar que a classe cultura temporária é a que tem maior presença na zona de amortecimento, com uma área atualmente de 44.408 ha. Esse aumento ocorreu pela redução das pastagens, cuja área possuía um valor de 11.114 ha. A área urbana também apresentou um aumento, atualmente possui uma área de 2.705 ha, porém esse aumento contribuiu para a redução da pastagem.

A Estação Ecológica se destaca com um aumento significativo da área. No ano de 2000, a sua área era de 1.598 ha, como aponta o Decreto Estadual 47.097, de 
18/09/2002 (ASSEMBLEIA GERAL DO ESTADO DE SÃO PAULO, 2002) a área foi ampliada e hoje apresenta um total de aproximadamente 1.713 ha. Outra classe de destaque é a silvicultura, durante esses 17 anos obteve um aumento significativo para a zona de amortecimento. A mata ciliar também apresentou um aumento significativo para ZA. Este aumento tem indicativo relacionado com o Código Florestal (BRASIL, 2012), que institui as regras gerais sobre onde e de que forma o território brasileiro pode ser explorado ao determinar as áreas de vegetação nativa que devem ser preservadas e quais regiões são legalmente autorizadas a receber os diferentes tipos de uso da terra.

A Lei n. 12.651/2012 define que a Área de Preservação Permanente é uma área protegida, coberta ou não por vegetação nativa, com a função ambiental de preservar os recursos hídricos, a paisagem, a estabilidade geológica e a biodiversidade, facilitar o fluxo gênico de fauna e flora, proteger o solo e assegurar o bem-estar das populações humanas. Porém, a Lei 12.651/2012 (Art. 61-A) estabelece que nas Áreas de Preservação Permanente seja autorizada a continuidade das atividades agrossilvipastoris, de ecoturismo e de turismo rural em áreas rurais consolidadas, isto é, não são áreas que possui uma proteção integral podendo ser utilizadas para fins econômicos (BRASIL, 2012).

É importante apontar que as áreas descobertas são transitórias, isto é, há períodos de entressafra, de preparo do solo para o plantio e o período que a cultura está no seu estágio vegetativo. No caso da cana-de-açúcar, esta possui o período de safra entre os meses de abril e maio, isto explica a presença de áreas descobertas.

Essa mudança drástica para a cana-de-açúcar traz problemas ambientais para o ambiente e para a população que mora próxima a esta área, como: a fuligem da queima da cana, o mau cheiro da vinhaça, a contaminação dos córregos com a utilização deste resíduo. Uma das práticas dessa drástica mudança que coloca em risco a preservação da biodiversidade é pulverização aérea de biocidas próximos à unidade de conservação. Provocam riscos de contaminação da flora, fauna e dos recursos hídricos, além da perda de espécies.

$\mathrm{Na}$ Tabela 2 apresenta a síntese das mudanças corridas nas principais categorias, ou seja, as perdas e ganhos das categorias. Pode observar que a cultura temporária se apresenta como a classe que mais ganhou área (12,29\%) correspondendo a maior área da zona de amortecimento. A pastagem também se destaca, porém como a classe que se obteve maior perda $(7,83 \%)$, está obteve-se 
perda, pois foi cedendo área para outras categorias. A área urbana teve-se um ganho relativamente pequeno em sua área (1,03\%). A floresta $(2,94 \%)$, EEA $(0,44 \%)$, silvicultura $(0,85 \%)$ não demonstrou mudanças significativas de suas áreas.

Tabela 2 - Comparativo de perda e ganho de cada uso entre os anos de 2000 e 2017

\begin{tabular}{ccccc}
\hline Classes & Perda (ha) & Perda (\%) & Ganho (ha) & Ganho (\%) \\
\hline EEA & & & & \\
Pastagem & 449 & 0,43 & 458 & 0,44 \\
Área Urbana & 8.224 & 7,83 & 1.269 & 1,21 \\
Silvicultura & 550 & 0,52 & 1.083 & 1,03 \\
Cultura Temporária & 829 & 0,79 & 895 & 0,85 \\
Solo exposto & 8.347 & 7,95 & 12.902 & 12,29 \\
Edificações & 3.851 & 0,04 & 4.560 & 0,09 \\
Mata ciliar & 43 & 3,67 & 95 & 4,34 \\
Floresta & 3.495 & 3,33 & 4.284 & 4,08 \\
\hline
\end{tabular}

Fonte: Elaborado pelos autores (2017).

O Mapa de Persistência (Figura 5) traz os usos que persistiram na zona de amortecimento durante esses dezessete anos. Pode-se observar que a categoria de uso que obteve maior área de persistência foi à cultura temporária. As categorias pastagem, área urbana, silvicultura e EEA também aparecem como uma área de persistência.

Figura 5 - Mapa de persistência de uso da terra na zona de amortecimento da Estação Ecológica de Assis

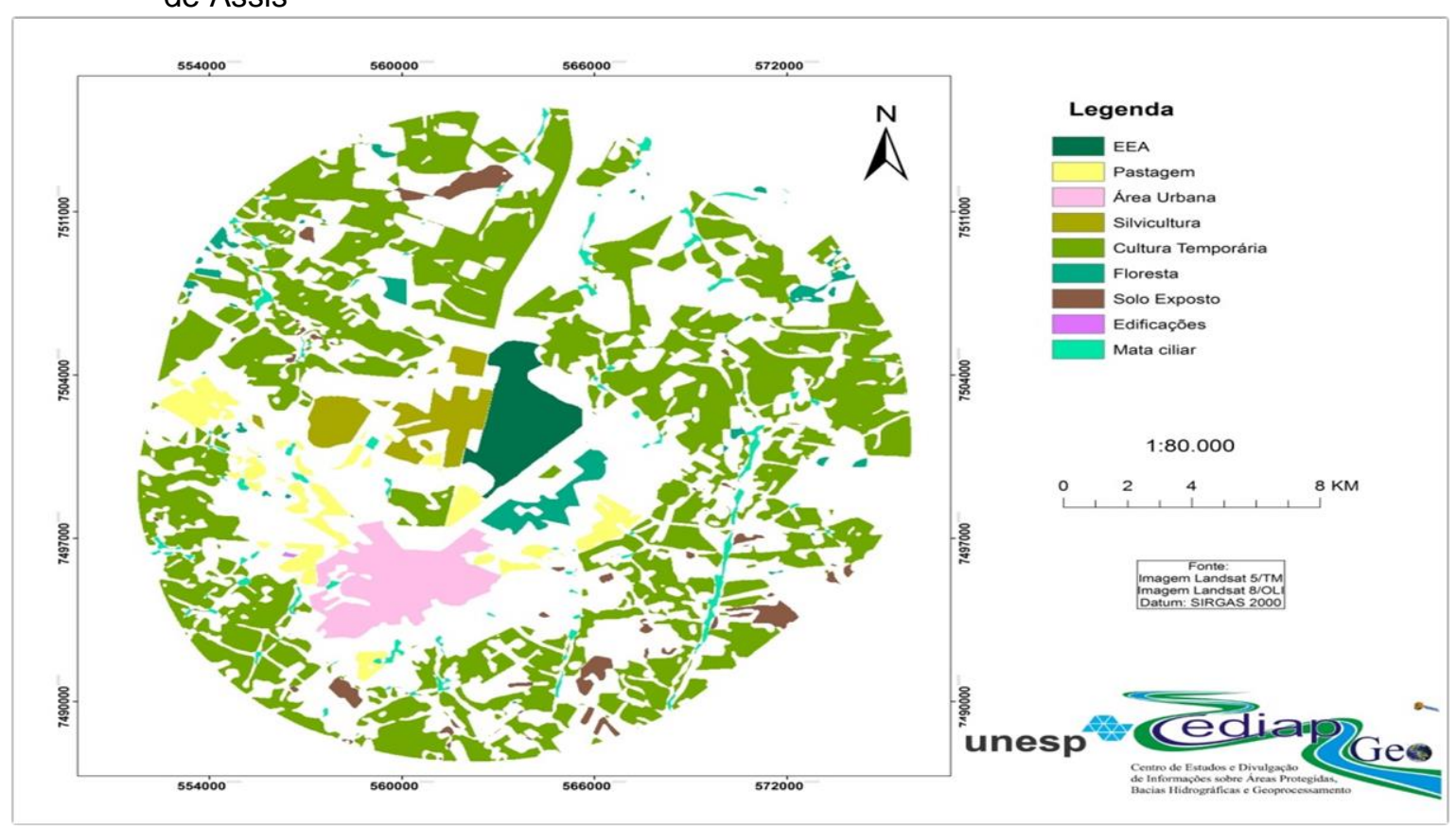

Fonte: Elaborado pelos autores (2017). 


\section{CONSIDERAÇÕES FINAIS}

Foi possível verificar as mudanças corridas entre os dezessete anos analisados e identificar as mudanças significativas para a Zona de Amortecimento. Através do módulo Land Change Modeler, destacamos a espacialização, a dinâmica e as transformações ocorridas neste período. Nota-se que a ZA hoje encontra-se tomada integralmente por usos que afetam a conservação da EEA e podendo gerar impactos negativos, como por exemplo: a cultura temporária.

Pode-se concluir que as técnicas de classificação foram precisas para as análises realizadas do uso da terra nas duas imagens em diferentes períodos, através da confirmação em campo. A utilização destes procedimentos permitiu mapear e identificar as mudanças ocorridas nesses períodos. As condições de isolamento entre a unidade e a deterioração desse fragmento de entorno dificultam o fluxo gênico de plantas e animais colocam em risco a sobrevivência das espécies nos fragmentos e na própria unidade de conservação. Essas mudanças sem uma devida preocupação podem trazer consequências mananciais, a fauna e principalmente a vegetação do Cerrado. Portanto, para a minimização desses problemas, é necessários uma forma de manejo adequado e um trabalho de sensibilização da população local.

Pode-se afirmar a hipótese do trabalho de que a utilização de dados orbitais pode contribuir ao monitoramento das UCs, e as mudanças no uso da terra, monitorando se a degradação ambiental na área tem-se intensificado.

Destaca-se com este trabalho a importância das técnicas de Sensoriamento Remoto, Geoprocessamento e análise espacial, que deram apoio à base de dados e à modelagem em ambientes SIG, considerada uma ferramenta importante para o auxílio no processo de tomada de decisão.

\section{REFERÊNCIAS}

ALVARENGA, A. S.; MORAES, M. F. Utilização de imagens LANDSAT: 8 para caracterização da cobertura vegetal. MundoGEO, p. 1, 10 jun. 2014.

ASSEMBLEIA GERAL DO ESTADO DE SÃO PAULO. Decreto ํㅜ 47.097, de 18 de setembro de 2002 - Amplia a Estação Ecológica de Assis, localizada no Município de Assis, criada pelo Decreto no 35.697, de 21 de setembro de 1992, objetivando o desenvolvimento de atividades científicas e educacionais. Diário oficial, ano 2002, p. 3, 2002. Disponível em: https://www.al.sp.gov.br/repositorio/legislacao/decreto/2002/decreto-47097-18.09.2002.html. Acesso em: 1 jun. 2020. 
BENSUAN, N. Conservação da biodiversidade em áreas protegidas. Rio de Janeiro: Editora FGV, 2006.

BONGIOVANNI, S. Caracterização geológica do município de Assis: a importância do estudo das coberturas cenozoicas. 2008. 233 f. Tese (Doutorado) - Curso de Pósgraduação em Geologia Regional, Geologia, Universidade Estadual Paulista, Rio Claro, 2008.

BRASIL. Congresso Nacional. Câmara dos Deputados. Estudo: zonas de amortecimento de unidades de conservação. Autor Roseli Senna Ganem. Brasília, mar. 2015.

BRASIL. Congresso Nacional. Câmara dos Deputados. Lei no 12.651, de 12 de maio de 2012. Dispõe sobre a proteção da vegetação nativa; altera as Leis nำs 6.938 , de 31 de agosto de 1981, 9.393, de 19 de dezembro de 1996, e 11.428, de 22 de dezembro de 2006; revoga as Leis nํs 4.771, de 15 de setembro de 1965, e 7.754, de 14 de abril de 1989, e a Medida Provisória n 2.166-67, de 24 de agosto de 2001; e dá outras providências. Brasília: Congresso Nacional, 2012. Disponível em: http://www.planalto.gov.br/ccivil 03/ ato20112014/2012/lei/l12651.htm. Acesso em: 1 jun. 2020.

BRASIL. Congresso Nacional. Câmara dos Deputados. Lei Federal № 9.985, de 18 de julho de 2000. Regulamenta o art. 225, § 1ํ, incisos I, II, III e VII da Constituição Federal, institui o Sistema Nacional de Unidades de Conservação da Natureza e dá outras providências, 2000.

BRASIL. Ministério do Meio Ambiente. Conselho Nacional do Meio Ambiente - CONAMA. Resolução CONAMA no 13, de 6 de dezembro de 1990. Estabelece diretrizes aos órgãos ambientais para o cálculo, cobrança, aplicação, aprovação e controle de gastos de recursos advindos de compensação ambiental, conforme a Lei no 9.985, de 18 de julho de 2000, que institui o Sistema Nacional de Unidades de Conservação da Natureza-SNUC e dá outras providências, 1990.

CREPANI,E.;DUARTE,V.;SHIMABUKURO,Y.E.;FIDALGO,E.C.C. Sensoriamento remoto e geoprocessamento no mapeamento regional da cobertura e uso atual da terra. Rev.

Geografia, Rio Claro, v. 27, n. 1, p. 119-135, abr. 2002.

CRIADO, R.C. Mudanças no uso e na cobertura da terra em municípios do pontal do Paranapanema de 1984 a 2014. Tese (Doutorado) - Universidade Estadual Paulista "Júlio de Mesquita Filho". Presidente Prudente, 2016.

FENGLER, F.H; SILVA, A.M; PECHE-FILHO, A; STORINO, M; RIBEIRO, A.I; MEDEIROS, G.A. Análise temporal da cobertura do solo na zona de amortecimento de reserva biológica. Revista Brasileira de ciências Ambientais, n. 25, set. 2012.

FRANCO, M.M.F.; MUNIZ, J.; NOVAS, M.F.B. Geotecnologia aplicada na análise temporal de índice de vegetação do Parque Estadual da Serra da Tiririca. In: XV SIMPÓSIO BRASILEIRO DE SENSORIAMENTO REMOTO, 15, 2011. [Anais...]. Curitiba, abr. 2011, p. 1942.

IBAMA. Plano de manejo da estação ecológica de assis. Assis, 2010. 172 p.

KLEIN, A. L. (Org.). Eugen Warming e o cerrado brasileiro: um século depois. São Paulo: Editora da Unesp, 2002. 156 p.

INSTITUTO BRASILEIRO DE GEOGRAFIA E ESTATÍSTICA. Manual técnico em geociências. 3. ed. Rio de Janeiro: IBGE, 2013.

Holos Environment (2021), 21 (2): 249-263. 261 
INSTITUTO BRASILEIRO DE GEOGRAFIA E ESTATÍSTICA. Cidades. Disponível em: https://cidades.ibge.gov.br/xtras/perfil.php?lang=\&codmun=350400\&search=\|linfogr\%E1 ficos :-informa\%E7\%F5es-completas. Acesso em: out. 2017.

KÖPPEN, W. Climatologia: con un estudio de los climas de la Tierra. Fondo de Cultura Economica, México, 1948.

LEITE, E. F.; ROSA, R. Análise do uso, ocupação e cobertura da terra na bacia hidrográfica do Rio Formiga, Tocantins. Observatorium: Revista Eletrônica de Geografia, v. 4, n.12, p. 90-106, dez. 2012.

OLIVEIRA, J.S.S. Índice de vegetação (BDVI, IVAS, IAF, NDWI) como subsídio à gestão do uso e ocupação do solo na zona de amortecimento da reserva biológica de Saltinho, Pernambuco. Dissertação (Mestrado) - Universidade Federal de Pernambuco. Recife, 2013.

PINHEIRO, E.S.; DURIGAN, G. Dinâmica espaço-temporal (1962-2006) das fitofisionomias em unidades de conservação do Cerrado no sudeste do Brasil. Revista Brasileira Botânica, São Paulo, v.32, n.3, p. 441-454, jul./set. 2009. https://doi.org/10.1590/S0100$\underline{84042009000300005}$

RIBEIRO, M.V; SILVA, T.M; ASSUNÇÃO, T.T. Uso de sensoriamento remoto para análise da zona de amortecimento em três unidades de conservação de proteção integral no estado de Goiás. Rev. Geo. UEG, Porangatu, v.6, n.1, p.112-124, jan./jun. 2017.

RICOBOM, A. E.; CANEPARO, S. C. Metodologia para geração de mapeamentos preditivos utilizando a cadeia de Markov e autômatos celulares - área piloto: perímetro urbano de Paranaguá - Paraná - Brasil. In: SIMPÓSIO BRASILEIRO DE GEOMÁTICA, 4., 2017; JORNADAS LUSÓFONAS - Ciências e Tecnologias de Informação Geográfica, 2., 2017. [Anais...]. Presidente Prudente, p. 300-308, 26 jun. 2017.

ROSENDO, J.S; ROSA, R. Análise da detecção de mudanças no uso da terra e cobertura vegetal utilizando a diferença de índice de vegetação. In: SIMPÓSIO BRASILEIRO DE SENSORIAMENTO REMOTO, 13., 2007. [Anais...]. Florianópolis, abr. 2007.

ROSSATTO, D.R; KOLB, R.M. Comportamento fenológico da liana Pyrostegia venusta (Ker Gawl.) Miers (Bignoniaceae) em área de cerradão na Estação Ecológica de Assis, SP,

Brasil. Revista Brasileira de Biociências, Porto alegre, v. 9, n. 3, p. 289-296, jul./set. 2011.

ROUSE, J.W.; HAAS, R.H.; SCHELL, J.A.; DEERING, D.W. Monitoring vegetation systems in the great plains with ERTS. In: Third ERTS SYMPOSIUM, 3., 1973. [Proceedings...]. NASA SP-351. Washignton, DC, v. 1, p. 309-317, 1973.

SANTOS, E.P; PIROLI, E.L. Detecção de mudanças no uso e cobertura da terra utilizando Land Change Modeler: o caso da bacia hidrográfica do Ribeirão do Rebojo, Pontal do Paranapanema. In: SIMPÓSIO BRASILEIRO DE SENSORIAMENTO REMOTO, 17., 2015. [Anais...].João Pessoa, PB, abr. 2015.

VIEIRA, D.J.E.; NUNES, G.M.; SILVA, T.S.F.; LENZI, I.L.C. Análise da mudança da cobertura da terra na região do Parque Estadual do Araguaia, MT, por meio de classificação orientada a objeto e dados Landsat 5 TM. In: SIMPÓSIO BRASILEIRO DE SENSORIAMENTO REMOTO, 16., 2013. [Anais...]. Foz do Iguaçu, abr. 2013. 
ZANATA, J.M. Mudanças no uso e cobertura da terra na bacia hidrográfica do Ribeirão Bonito, município de Avaré e Itatinga-SP. Dissertação (Mestrado). Universidade Estadual Paulista "Júlio de Mesquita Filho". Presidente Prudente, 2014. 